\title{
Ligno: material compósito com resíduo de madeira
}

Ligno: composite material from wood waste

CORRÊA, Glaucinei Rodrigues; Escola de Arquitetura - UFMG

glaucinei@ufmg.br

POLICARPO, Alessandro de Oliveira; Escola de Arquitetura - UFMG

alessandropolicarpo@me.com

\section{Resumo}

Este artigo apresenta os resultados da segunda etapa de uma pesquisa sobre o desenvolvimento tecnológico de um material compósito sustentável, a partir de resíduos gerados pela indústria moveleira. As conclusões aqui demonstradas estão fundamentadas em pesquisa realizada previamente nas empresas do setor localizadas na região metropolitana de Belo Horizonte. Seu desenvolvimento compreende: seleção dos resíduos; desenvolvimento do material compósito; desenvolvimento de alternativas (produtos e serviços) para utilização dos resíduos; projeto e acompanhamento da fabricação dos moldes; e fabricação dos produtos utilizando a nova tecnologia. Como resultado desta etapa, conseguiu-se desenvolver a composição do material, sistematizar sua dinâmica de produção, verificar sua viabilidade produtiva e gerar alternativas de aplicação. A tecnologia desenvolvida surge como uma possibilidade sustentável para a destinação correta e, além de tudo, lucrativa desses resíduos, que, apesar de sua relevância, não recebem o devido tratamento por parte dos responsáveis.

Palavras Chave: resíduos; indústria moveleira; design.

\begin{abstract}
This paper presents the results of the second stage of a research that deals with the technological development of a sustainable composite material made from the wood waste generated by the furniture industry. The results shown here are anchored on a research previously conducted along with companies of the sector based in the metropolitan area of Belo Horizonte and its development consists of granulometric classification of the waste; development of the composite material; development of alternatives of products and services to apply the composite material; project and manufacture of the moulds, manufacture of products using the new technology. As a result of this stage, it was possible to set the composition of material, systematize its production dynamics, verify its productive feasibility and generate alternatives for applications. The developed technology emerges as a sustainable possibility for the correct and, above all, profitable disposal of these wastes that, despite their relevance, do not receive the right treatment by those responsible.
\end{abstract}

Keywords: waste; furniture industry; design. 


\section{Introdução}

A indústria de móveis no Brasil se destaca na cadeia produtiva da madeira por meio das marcenarias e dos fabricantes de móveis. Os principais resíduos gerados são consequência direta da transformação da madeira maciça ou de painéis durante a produção dos móveis. Embora a Lei 12.305, de 2010, tenha instituído a Política Nacional de Resíduos Sólidos, que dispõe sobre as diretrizes relativas à gestão integrada e ao gerenciamento dos resíduos sólidos, são poucas as iniciativas de programas de gerenciamento ou de aproveitamento de resíduos na indústria moveleira nacional. A maioria das indústrias ainda destina os resíduos para aterros sanitários, para a forração de granjas ou, simplesmente, para a queima a céu aberto.

No polo moveleiro de Belo Horizonte, segundo Corrêa et al. (2016), há 134 empresas associadas ao Sindicato das Indústrias do Mobiliário (Sindimov-MG), das quais 84 são de móveis. Elas geram 298 toneladas de resíduos - aparas e pó de MDF e serragem de madeira maciça - por mês, das quais apenas $16 \%$ têm destinação correta -, ou seja, são incineradas ou coprocessadas. Esses resíduos podem apresentar alguma periculosidade quando não têm disposição adequada, especialmente se estiverem estocados de maneira inadequada, próximo às instalações industriais ou aglomerações urbanas.

Nesse cenário, desenvolveu-se um novo material compósito, por meio do qual se aproveitam os resíduos gerados pelas indústrias. É composto de resíduos da própria indústria moveleira e de adesivo, que são prensados. Também se desenvolveram produtos nos quais foi utilizado o novo material. Destaca-se, ainda, a criação de uma marca para a nova tecnologia, denominada LIGNO. Com base nessa nova tecnologia, o produto sai pronto do molde, não necessitando de nenhuma operação de usinagem ou corte, mas apenas a aplicação de alguma proteção, como tinta ou verniz. Além disso, pode ser transferida com relativa facilidade para as empresas do setor que queiram aproveitar seus resíduos. Com a fabricação de produtos utilizando essa nova tecnologia, as empresas podem contribuir para o meio ambiente, deixando de descartar seus resíduos em aterros ou a céu aberto, e para a sociedade, gerando mais emprego e renda, além de diminuir gastos, por não terem que arcar financeiramente com o descarte dos resíduos. Sobretudo, podem obter lucro com a fabricação de produtos de alto valor agregado utilizando os próprios resíduos.

\section{A reinserção de resíduos de madeira na cadeira produtiva}

Artigo publicado por Corrêa et al. (2016) alerta para o alto volume de resíduos produzidos, porém sem destinação adequada. Nesse sentido, há algumas pesquisas documentadas que se desenvolvem sob a premissa de reintroduzir esses resíduos na cadeia produtiva - por exemplo, em Abreu et al. (2009) e Pereira et al. (2010) -, indicando a plena viabilidade de uma solução no âmbito dessa abordagem, mas que não conseguem, em sua grande maioria, materializar resultados que possam ser facilmente transferidos para a realidade industrial e que, sobretudo, tragam, além do positivo impacto ambiental, possibilidades de exploração comercial.

Hexion Inc (2010), na patente US7803855B2, documenta o desenvolvimento de um compósito realizado a partir da mistura de fenol formaldeído (PF), éster de polivinila (PVA), proteína de origem animal ou vegetal e madeira. A tecnologia tem o propósito de melhorar as propriedades do material quanto à estabilidade e à força das ligações internas, diminuir os níveis da liberação do fenol formaldeído (PF) na produção das placas e retirar a ureia nos processos de confecção da composição. O processamento deste compósito prevê as seguintes etapas: a) 
mistura da resina formada por fenol formaldeído (PF), éster polivinilico (PVA) e proteína de soja (origem vegetal); b) aplicação da resina na madeira, por meio de pulverização e mistura dos elementos de maneira uniforme; e c) os pedaços de madeira revestidos com a resina são soltos em suas matrizes contendo o formato de placas e posteriormente são prensadas em uma temperatura de 140 a $170^{\circ} \mathrm{C}$.

Em sentido mais próximo dos objetivos desta pesquisa, a Ciatec A.C (2013) desenvolveu, como demonstrado na patente $M X 2011008552$, um composto com o resíduo sólido de madeira e resina polimérica PET. O processamento deste compósito contempla as seguintes etapas: a) verificação dos materiais com relação à sua consistência e umidade; b) pesagem do polímero e da serragem de madeira; c) os componentes são misturados em alta temperatura $\left(240-265^{\circ} \mathrm{C}\right)$ no processo de extrusão de dupla rosca, para garantir uma forma homogênea; e d) o composto é transferido para um molde em elevada temperatura, para ser comprimido em uma prensa, resultando no produto final.

Exemplificando a abordagem de produção por extrusão, extensivamente encontrada em trabalhos relacionados e análogos, a Fundação de Amparo à Pesquisa do Estado de São Paulo (2009), na patente PI 0802175-9 A2, descreve a utilização da farinha de resíduo de madeira, um subproduto da usinagem de madeira não impregnada, tipo pinus caribea, pinus elliotti, eucaliptus, em conjunto com o resíduo de MDF (Médium Density Fiberboard), e sua compostagem com termoplásticos virgens, pós-consumo e aparas industriais. O invento em questão demonstra o desenvolvimento de processos de manufatura de concentrados de compósitos polímero-madeiraMDF utilizados para a obtenção de componentes injetados e a extrusão de perfis a partir desses compósitos em geometrias predefinidas por matrizes de extrusão.

Como elucidado nos trabalhos citados, é evidente a viabilidade da reintegração dos resíduos produzidos pela indústria moveleira em seus respectivos setores produtivos. Porém, fica nítida a carência de aprofundamento na real aplicação de todos esses processos em soluções viáveis e tangíveis que possam, de fato, trazer um impacto prático para a realidade do setor. Alguns fatores contribuem para esta conclusão, destacando-se a exploração de processos produtivos dispendiosos, como a injeção ou a extrusão, abordada pela Fundação de Amparo à Pesquisa do Estado de São Paulo (2009) e inúmeros outros autores com propostas análogas. Segundo o Panorama do Setor Moveleiro no Brasil (2006), produzido pela Associação Brasileira das Indústrias do Mobiliário (ABIMÓVEL), 74\% das indústrias nacionais do setor são microempresas de até 9 funcionários. Portanto, seria incompatível propor a adoção de novas plantas produtivas de alto investimento como requisito para viabilizar o reaproveitamento dos resíduos aqui abordados. Nas demais propostas que fogem a esse padrão, notam-se resultados que não extrapolam o âmbito da termoformagem de placas e painéis. Ou seja, o produto do processo de reaproveitamento entraria, neste cenário, em competição com as placas de madeira reconstituída originárias, cuja produção ocorre em plantas industrializadas, tornando seu produto final muito mais barato em relação ao material reaproveitado. Para contornar essas questões levantadas, este estudo propõe um processo de manufatura por termoformagem em matriz fechada para a fabricação de produtos cuja morfologia será exatamente a contraforma do molde utilizado. Desse modo, consegue-se obter formas complexas para a aplicação em produtos de alto valor agregado, sem a necessidade de posterior usinagem ou tratamento. $O$ adesivo utilizado é o de poliacetato de vinila (PVA), por se apresentar economicamente mais acessível e, ainda, por não ser amplamente explorado neste tipo de aplicação. 


\section{Procedimentos metodológicos}

Para atingir os resultados almejados, foram empregados os seguintes procedimentos:

- Seleção dos resíduos. Tendo como referência o resultado da pesquisa dos resíduos realizado nas empresas, correspondente à primeira etapa dessa pesquisa (CORRÊA et al., 2016), decidiu-se trabalhar com os dois tipos de resíduos mais utilizados pelas indústrias moveleiras pesquisadas madeira maciça (peroba) e MDF - para os testes. Compreendeu três procedimentos: a) homogeneização dos resíduos, para garantir que a amostra representaria o todo; b) análise granulométrica da amostra de cabeça, por peneiramento a seco, para se ter uma noção da divisão granulométrica dos resíduos, mediante utilização de um peneirador vibratório suspenso para os resíduos de MDF, em 14 peneiras, variando de aberturas de $0,106 \mathrm{~mm}$ a $4,75 \mathrm{~mm}$, e para os resíduos de peroba, 15 peneiras, variando de $0,212 \mathrm{~mm}$ a $12,5 \mathrm{~mm}$; e c) peneiramento exaustivo dos resíduos.

- Desenvolvimento do material compósito. Compreendeu duas fases: a fabricação das placas, para a retirada dos corpos de prova; e b) ensaios físico-mecânicos, para a caracterização do material. Para a fabricação das placas, utilizaram-se dois grupos do resíduo de $\operatorname{MDF}(>0,106 \mathrm{~mm}$ e $<0,106 \mathrm{~mm})$ e um do de peroba $(>2,36 \mathrm{~mm})$, que representavam maior quantidade na classificação granulométrica. Para os testes iniciais de prensagem, utilizaram-se 12 tratamentos (Tabela 1).

Tabela 1 - Especificação de cada um dos 12 tratamentos, demonstrando o tipo de resíduo, o tamanho das partículas, 0 adesivo utilizado e a porcentagem.

\begin{tabular}{|c|c|c|c|c|}
\hline Tratamento & Resíduo & Tamanho & Adesivo & $\%$ \\
\hline 1 & MDF & $>0,106$ & PVA & 20 \\
\hline 2 & MDF & $>0,106$ & Poliuretano vegetal & 20 \\
\hline 3 & MDF & $<0,106$ & PVA & 20 \\
\hline 4 & MDF & $<0,106$ & Poliuretano vegetal & 20 \\
\hline 5 & PEROBA & $>2,36$ & PVA & 20 \\
\hline 6 & PEROBA & $>2,36$ & PVA & 20 \\
\hline 7 & MDF & $>0,106$ & PVA & 40 \\
\hline 8 & MDF & $<0,106$ & PVA & 40 \\
\hline 9 & PEROBA & $>2,36$ & Poliuretano vegetal & 40 \\
\hline 10 & PEROBA & $>2,36$ & Poliuretano vegetal & 40 \\
\hline 11 & MDF & $>0,106$ & Poliuretano vegetal & 40 \\
\hline 12 & MDF & $<0,106$ & & \\
\hline
\end{tabular}

Fonte: Elaborada pelos autores

Os procedimentos para a fabricação das placas compreenderam: a) pesagem do resíduo e do adesivo; b) encolamento, isto é, aspersão do adesivo no resíduo com pistola de pintura e mistura da massa, para homogeneizar o material; c) pesagem da quantidade, para se ter uma densidade de $650 \mathrm{~kg} / \mathrm{m}^{3}$; d) formação do colchão na prensa (Fig. 1); e) prensagem: 6 minutos com 12 toneladas de pressão a $190^{\circ} \mathrm{C}$. As placas foram prensadas todas com $6 \mathrm{~mm}$ de espessura e em torno de $220 \mathrm{~mm}$ de largura e comprimento. 
Figura 1: Formação do colchão na prensa

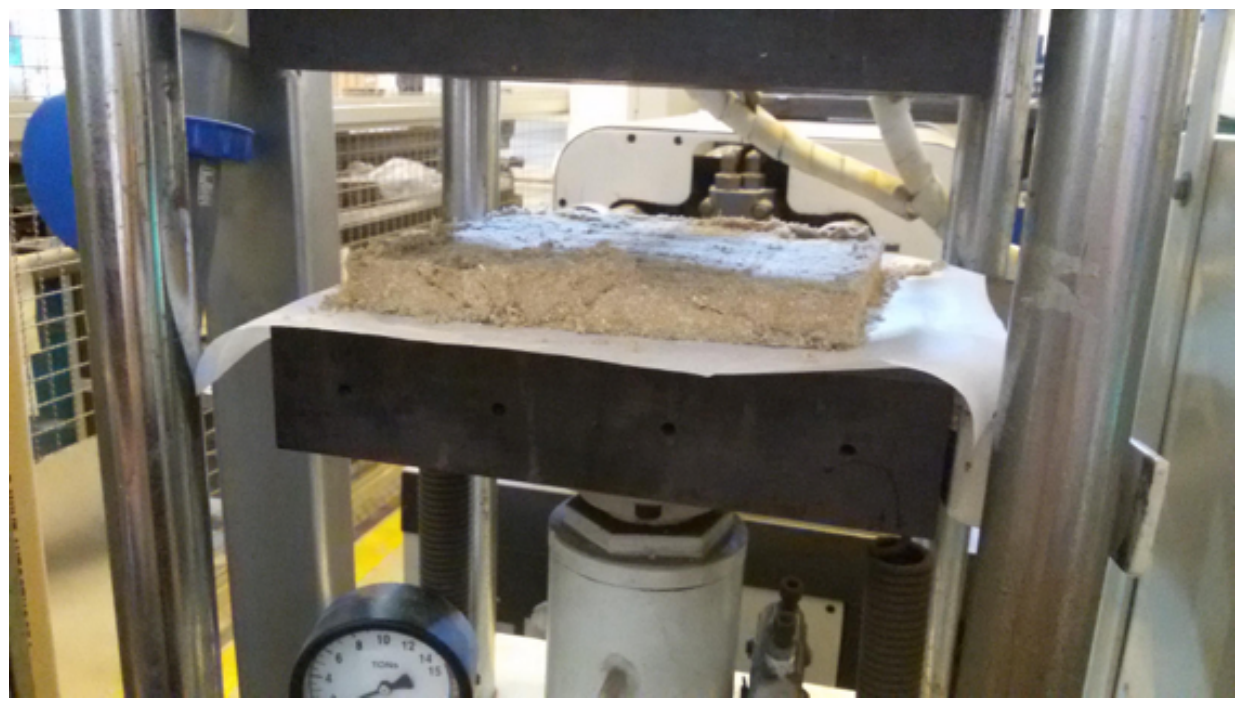

Fonte: Elaborada pelos autores.

Figura 2: Placa depois de prensada

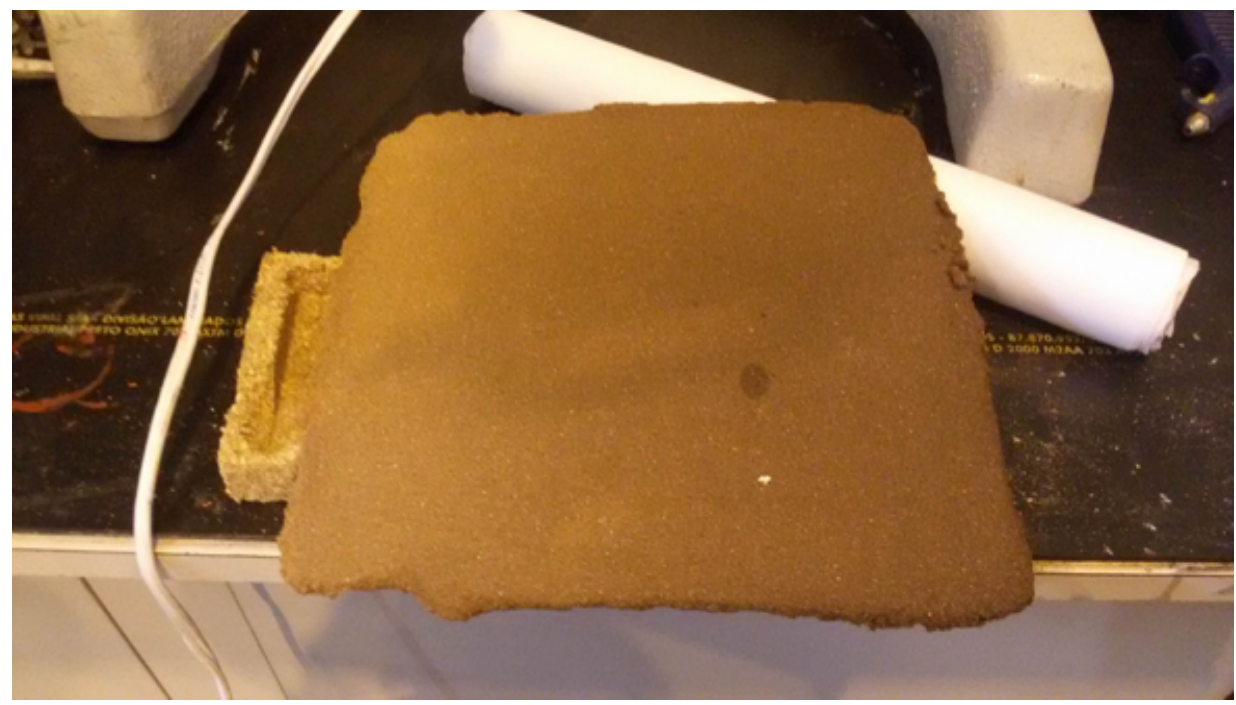

Fonte: Elaborada pelos autores.

Para os testes físico-mecânicos, utilizou-se como referência a norma ABNT NBR 14810 - Painéis de partículas de média densidade - Parte 2: requisitos e métodos de ensaio. Para cada tratamento foram fabricadas três placas, nas quais foram retirados os corpos de prova para os ensaios de resistência à flexão estática (Fig. 3). Ao total, foram cinco corpos de prova para cada tratamento, com dimensões de $6 \mathrm{~mm} \times 50 \mathrm{~mm} \times 170 \mathrm{~mm}$, conforme determina a norma técnica. 
Figura 3: Ensaio de resistência à flexão estática na máquina universal de ensaios

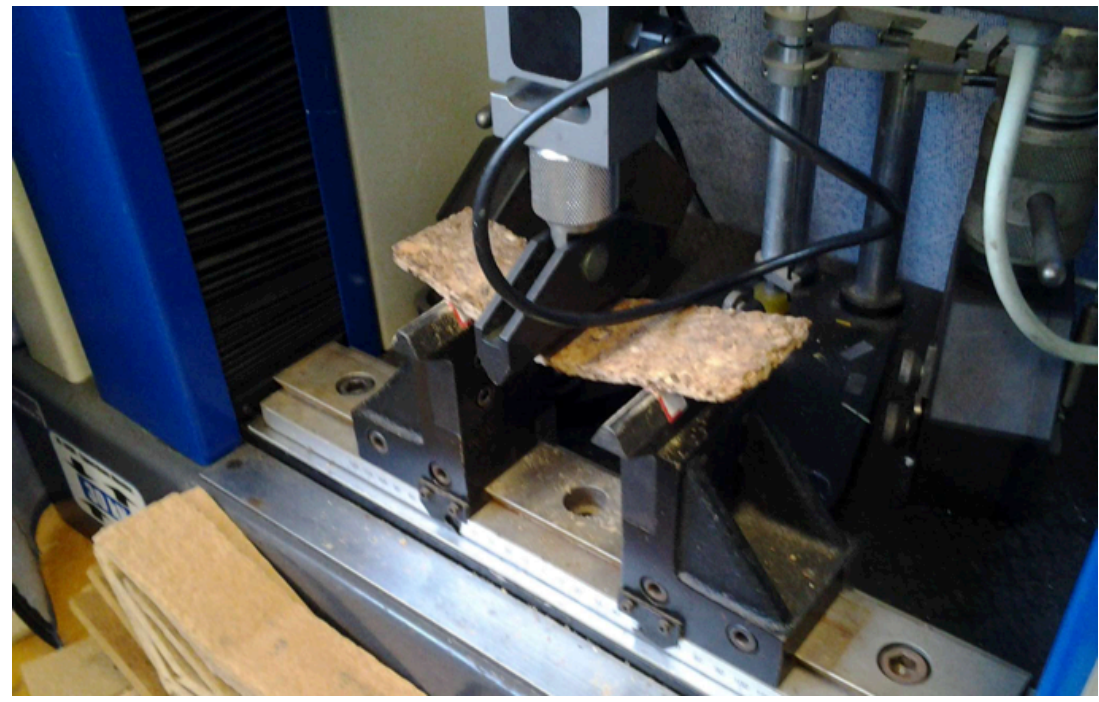

Fonte: Elaborada pelos autores.

- Desenvolvimento de alternativas (produtos e serviços) para a utilização dos resíduos gerados. Procedeu-se, inicialmente, ao mapeamento das possibilidades e oportunidades. Foram muitas as possibilidades estudadas, como, módulo para divisão de ambientes, produtos decorativos, vaso para plantas, cachepot, bandeja, vasilhas para guardar e servir, suporte para Notebook e suporte para vinhos. Para essa etapa utilizou-se desenhos, modelos tridimensionais feitos à mão, modelamento virtual de algumas peças e também, para alguns projetos, fez-se impressão 3D.

- Projeto e acompanhamento da fabricação dos moldes. Fez-se o projeto para três moldes. Além do projeto, fez-se o acompanhamento da fabricação na empresa especializada. Os moldes foram confeccionados de modo a se ter o controle da temperatura independente para cada uma das partes, inferior (parte fêmea) e superior (parte macho).

- Novos testes mecânicos de resistência a flexão estática. A partir da fabricação do molde para a produção de uma placa, fizeram-se testes mecânicos do novo material.

- Fabricação dos produtos. Para cada tipo de produto, fizeram-se diversos testes, os quais variaram: a quantidade de adesivo, a quantidade e o tipo de resíduo, o tempo de prensagem e a temperatura.

\section{Resultados}

\subsection{Desenvolvimento de nome e marca para o projeto}

Uma das primeiras atividades deste projeto consistiu na criação de nome e marca que pudessem ser mais facilmente identificadas pelo público em geral. Foram várias as alternativas criadas. A escolhida foi: Projeto LIGNO: uso de resíduos de madeira para fabricação de produtos (Figura 4). 
Figura 4: Nome e marca desenvolvida para o projeto

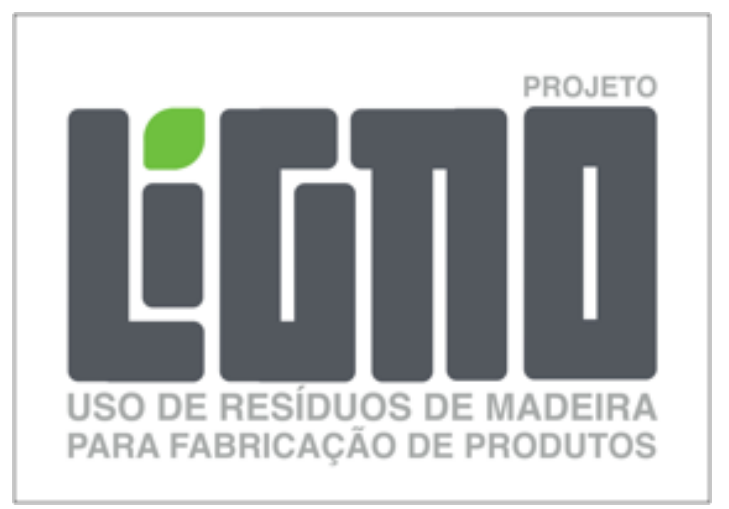

Fonte: Elaborada pelos autores.

\subsection{Análise Granulométrica da Amostra de Cabeça por Peneiramento a Seco}

A análise granulométrica do resíduo de MDF pode ser observada no Gráfico 1. Ao todo, foram 14 peneiras, que variaram de $0,106 \mathrm{~mm}$ a $4,75 \mathrm{~mm}$. Observa-se que quase metade da quantidade desse resíduo (43,5\%) corresponde ao tamanho de resíduo inferior a 0,106mm.

Gráfico 1: Análise granulométrica do resíduo de MDF, demonstrando a porcentagem retida em cada peneira.

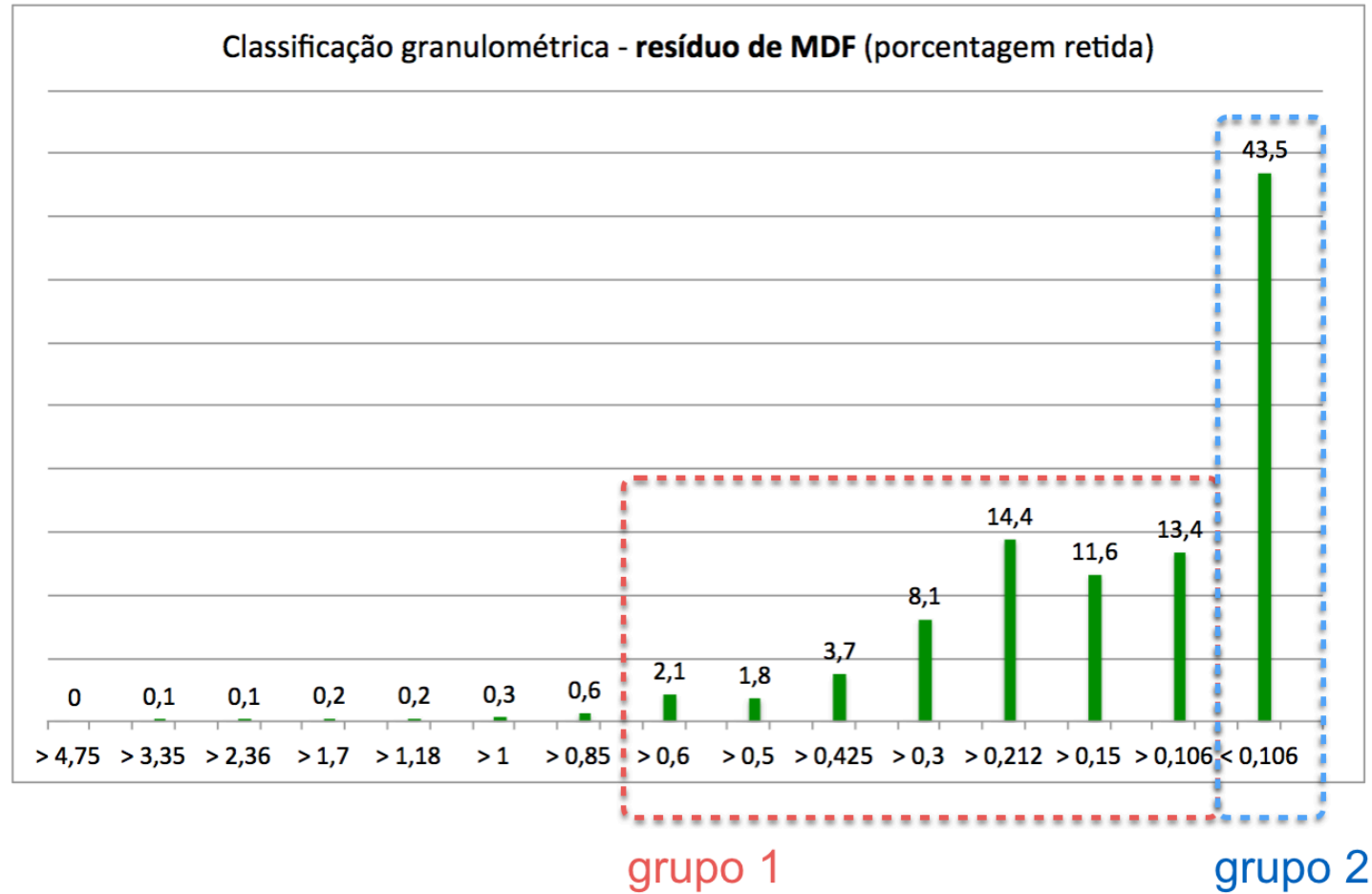

Fonte: Elaborado pelos autores.

Para os primeiros testes de desenvolvimento do material compósito, os resíduos de MDF foram agrupados / peneirados em duas partes, de modo a se ter uma compatibilização dos tamanhos das partículas: grupo 1) resíduos entre $0,85 \mathrm{~mm}$ e $0,106 \mathrm{~mm}$; e grupo 2) resíduos inferiores a $0,106 \mathrm{~mm}$. Os resíduos superiores a $0,85 \mathrm{~mm}$ foram descartados, por representarem uma pequena quantidade. 
A análise granulométrica do resíduo de peroba (Gráfico 2) compreendeu 15 peneiras, as quais variaram de $0,212 \mathrm{~mm}$ a $12,5 \mathrm{~mm}$.

Gráfico 2: Análise granulométrica do resíduo de peroba demonstrando a quantidade retida em cada peneira.

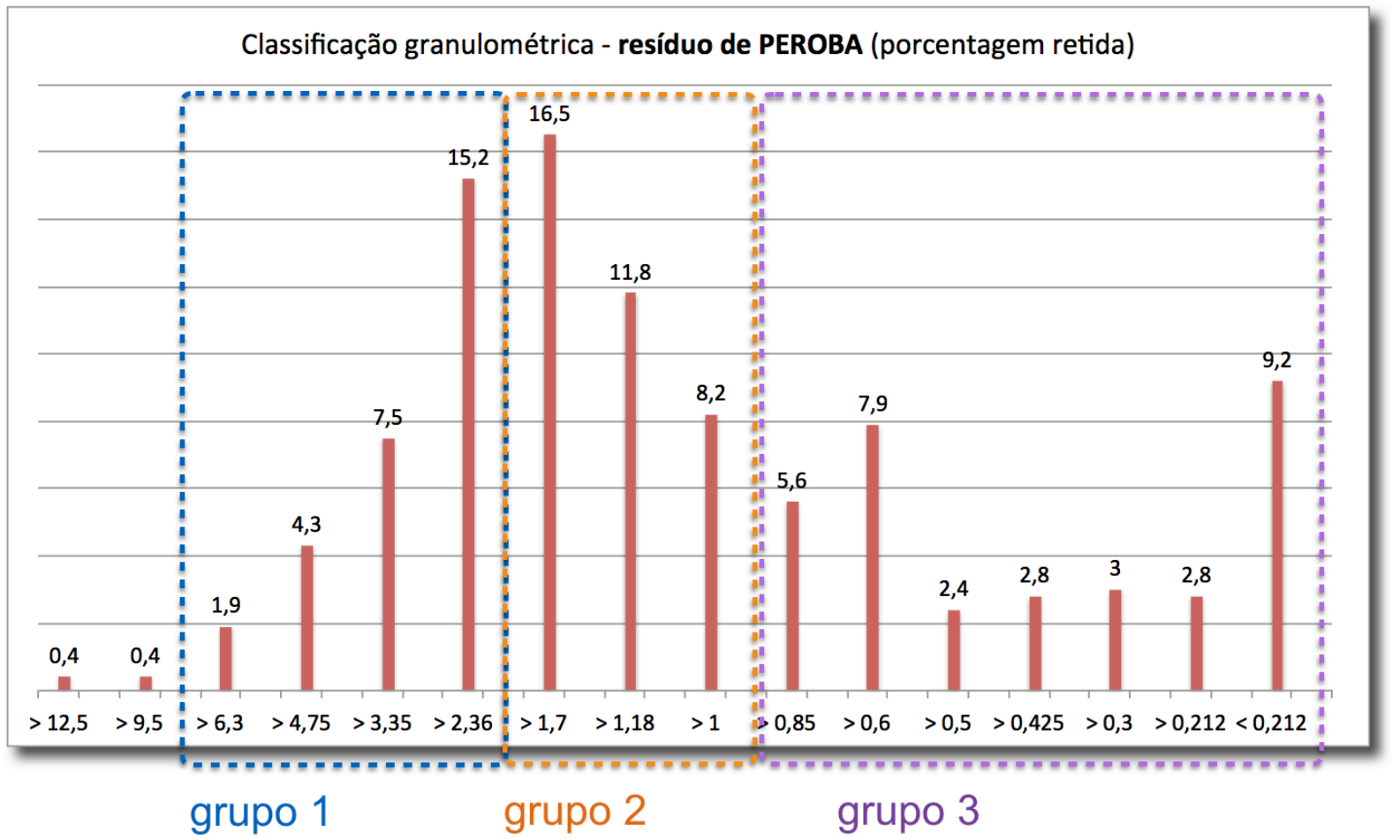

Fonte: Elaborado pelos autores.

Para o peneiramento, os resíduos de peroba foram divididos em três partes: grupo 1) resíduos inferiores a 9,50 $\mathrm{mm}$ e superiores a 2,36mm; grupo 2) resíduos inferiores a 2,36mm e superiores a 1,00mm; grupo 3) resíduos que passaram na peneira de $1,00 \mathrm{~mm}$. Os resíduos retidos na peneira de $9,50 \mathrm{~mm}$ foram descartados.

Esse agrupamento dos resíduos é importante para compatibilizar o tamanho das partículas, o que propicia melhor homogeneidade e qualidade das propriedades do material.

\subsection{Ensaios de Resistência à Flexão Estática}

Os resultados dos ensaios de resistência à flexão estática podem ser vistos no Gráfico 3.

Os valores de resistência à flexão estática ficaram inferiores se comparados às chapas de madeira reconstituída, como MDP e MDF. Mas o objetivo deste projeto, conforme já apontado, não é competir com as matérias primas já estabelecidas no mercado, como essas placas, por exemplo. A proposta deste projeto de pesquisa é que, ao ser prensado em matriz própria, específica, o produto já saia pronto, não necessitando de nenhuma outra operação ou procedimento de corte ou usinagem, somente aplicação de algum tipo de proteção, como verniz ou tinta. A maioria dos resultados de resistência à flexão estática atende aos objetivos do projeto. 
Gráfico 3: Resultado do ensaio de resistência à flexão estática para cada um dos 12 tratamentos.

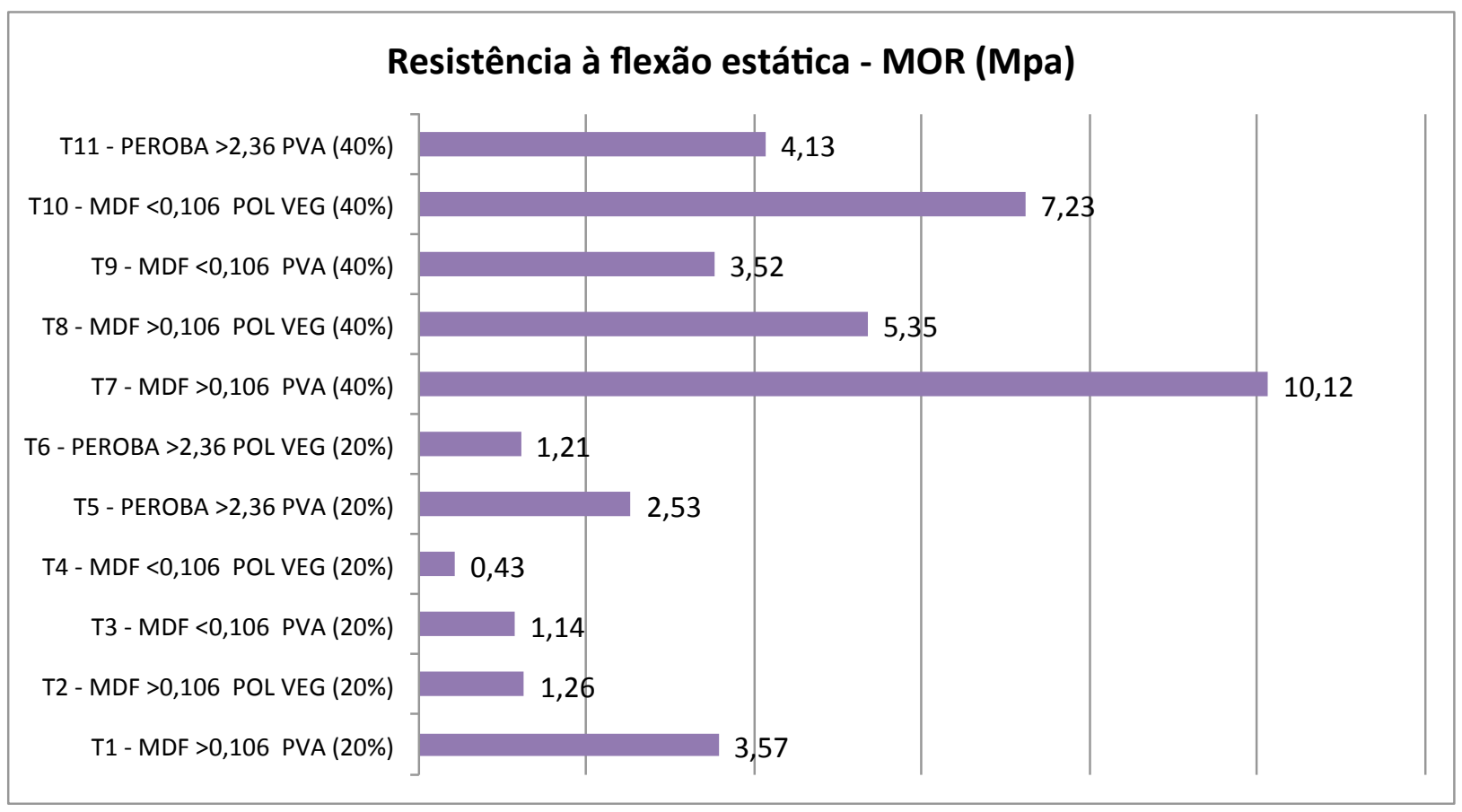

Fonte: Elaborado pelos autores.

A partir desses resultados, podem-se obter algumas conclusões. Por exemplo: que as placas com quantidade maior de adesivo (40\%) tiveram valores maiores para o MOR; e houve grande variedade dos resultados, talvez, relacionada aos procedimentos utilizados na fabricação das placas, embora se tenha tentado estabelecer o mesmo procedimento para a produção de todas as placas.

Optou-se por dar continuidade aos testes com a fabricação em matriz fechada utilizandose o adesivo de PVA, por ser mais acessível, por apresentar melhor trabalhabilidade e por ser à base de água, quando comparado ao adesivo de poliuretano vegetal.

\subsection{Desenvolvimento de alternativas}

Foram diversos produtos desenvolvidos durante a fase de geração de alternativas, na qual se priorizaram critérios que possibilitassem a maior experimentação possível com o novo material. A seguir, destaca-se a imagem (rendering) dos mais representativos.

Em função do investimento financeiro utilizados na fabricação dos moldes, optou-se por levar adiante dois desses produtos: o porta-copo e o bowl. O valor do molde da luminária (um dos produtos selecionados) ultrapassou o recurso concedido para o projeto, inviabilizando sua fabricação.

Optou-se por fabricar primeiro o molde do porta-copo, por ser menor e, consequentemente, mais barato. Havia a necessidade de experimentar diversos procedimentos, como, variações em relação à quantidade de adesivo, de resíduo e do tempo de prensagem e sobretudo, entender como funcionaria a fabricação desse produto com o novo material (Figura 5). 
Figura 5: Produtos desenvolvidos: linha de bowl, luminária e porta-copos

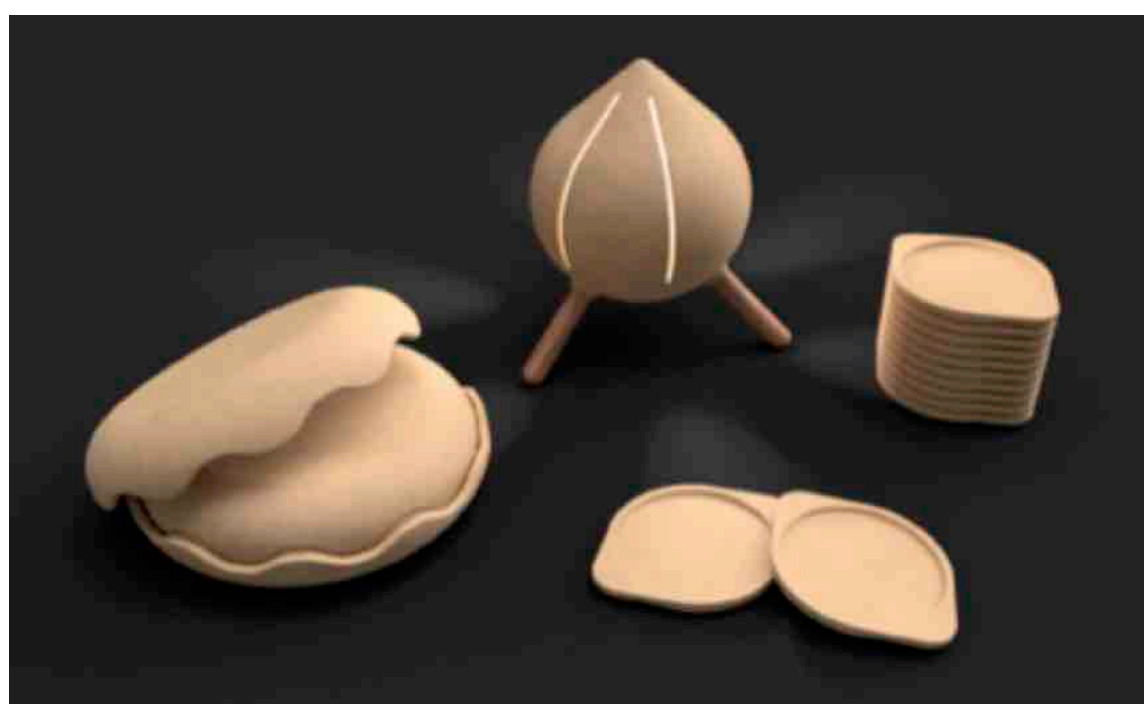

Fonte: Elaborada pelos autores.

Com o primeiro molde pronto, deu-se início aos testes de fabricação do produto portacopo. Foi necessário fazer diversas alterações no molde, como aumentar a folga entre macho e fêmea, criar saídas de gás e colocar alça para facilitar o manuseio. Ter experimentado o processo com o molde do porta-copo foi um grande aprendizado e todas as alterações realizadas foram consideradas no projeto de fabricação do próximo molde: o do bowl.

No bowl, havia diferenças significativas em relação ao porta-copo que poderiam gerar outros resultados. Consequentemente, outras soluções seriam necessárias. Por exemplo, o portacopo é praticamente plano, e este produto, o bowl, tem abas verticais nas laterais. As diferenças do bowl em relação ao porta-copo foram significativas para a fabricação do produto, tornando-se necessário realizar diversos ajustes no molde para conseguir produzir o produto.

Após a fabricação desses moldes, decidiu-se fabricar uma terceira matriz que originasse uma placa plana de $170 \mathrm{~mm} \times 170 \mathrm{~mm} \times 6 \mathrm{~mm}$, que permitissem testar alguns procedimentos de usinagem e corte deste novo material. Assim como nos demais moldes, ocorreram muitos problemas. Para conseguir produzir placas com esse molde, e foram necessários diversos ajustes.

Além dos testes de corte, a partir desse molde, fabricaram-se algumas placas, para realizar novamente os testes mecânicos de resistência à flexão estática. Utilizaram-se resíduos de MDF do grupo 1 (entre 0,106 e 0,6mm) e dois grupos de resíduos de uma outra madeira, o jequitibá (também encontrado em grande quantidade no Polo Moveleiro de $\mathrm{BH}$ ), grupo 1 (entre 1,0 e $1,7 \mathrm{~mm}$ ) e grupo 2 (entre 0,212 e 0,85mm). Os resultados podem ser observados no Gráfico 4 . 
Gráfico 4: Resultado do teste de resistência à flexão estática a partir da matriz fechada da placa

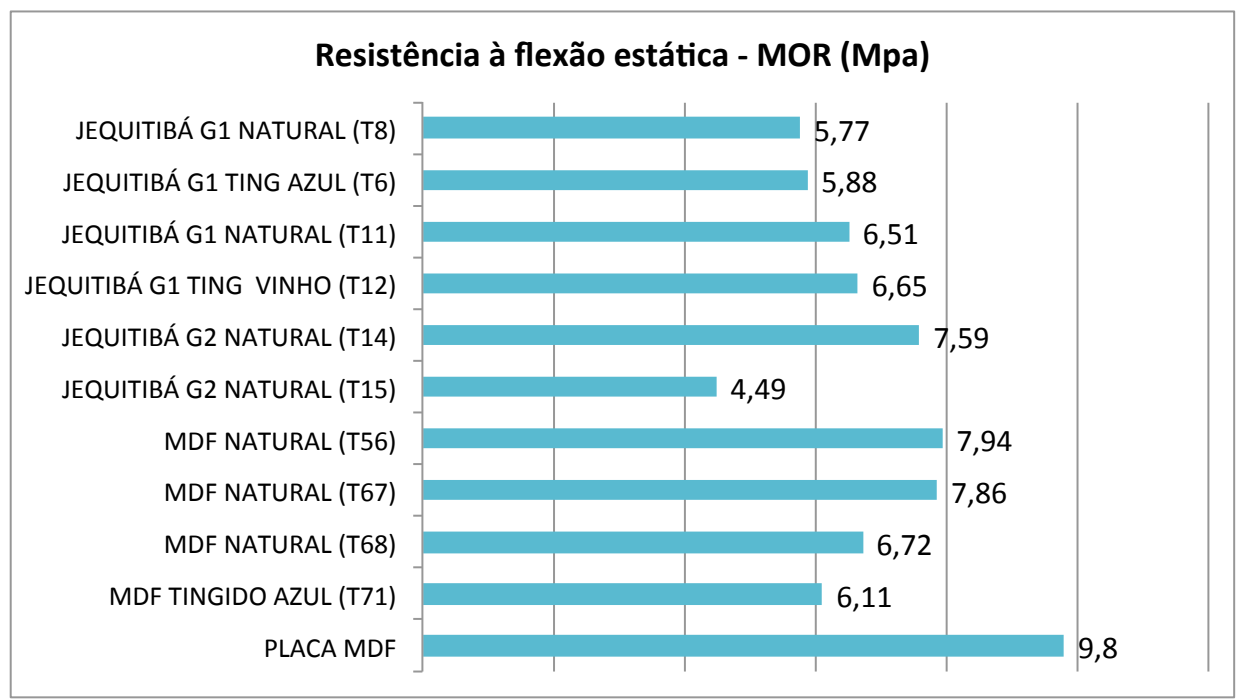

Fonte: Elaborado pelos autores.

Para efeito de comparação, os mesmos testes foram realizados com uma amostra (corpo de prova) de uma placa de MDF de um dos fabricantes nacionais.

Constatou-se que os resultados foram melhores que os dos primeiros testes, aqueles realizados com os corpos de prova fabricados em matriz aberta. Notou-se também, que houve menor variação desses em relação aos com matriz aberta. Outro fator importante para essa pesquisa é que nesses últimos ensaios mecânicos os valores encontrados para o teste de MOR para o novo compósito foram próximos aos da placa de MDF. Esse resultado demostra que o material tem resistência equivalente às placas disponíveis no mercado.

\subsection{Projeto e acompanhamento na fabricação dos moldes}

Para cada um dos moldes foi necessário fazer o projeto técnico e o acompanhamento na ferramentaria que os produziu. Em média, o tempo de fabricação de cada um foi de dois meses (Figura 6).

Figura 6: Molde do porta-copo aberto.

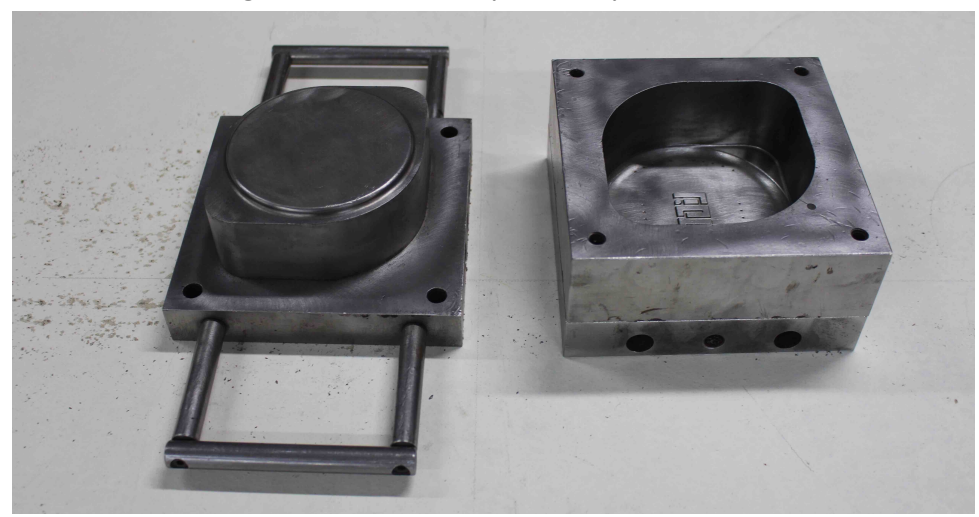

Fonte: Elaborada pelos autores. 
Além dos moldes, foi necessário investir em uma central de aquecimento (Fig. 7). Este componente único pode ser adaptado em todos os moldes. Com ele, é possível fazer o controle de temperatura de cada uma das partes dos moldes (parte macho e parte fêmea), o que permitiu experimentar as diversas temperaturas testadas durante a fabricação das peças.

Figura 7: Central de controle de temperatura.

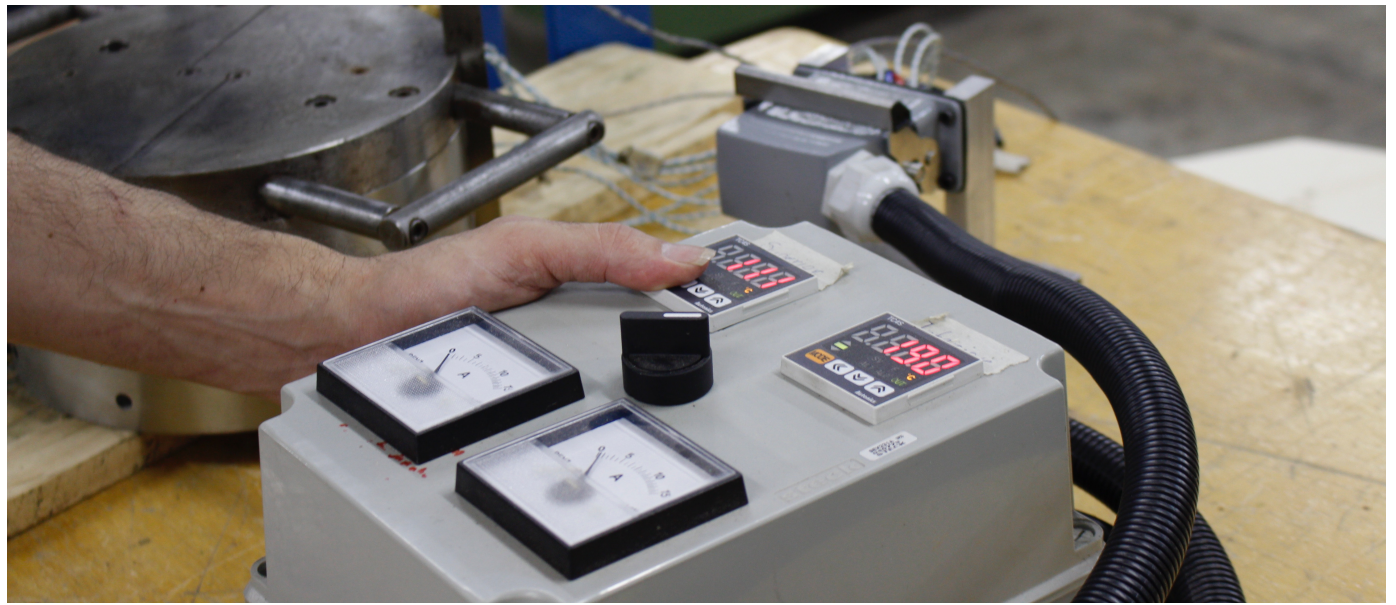

Fonte: Elaborada pelos autores.

\subsection{Fabricação dos produtos}

Optou-se por fabricar produtos com os dois tipos de resíduos: o de MDF e o de madeira maciça.

Após vários experimentos, concluiu-se que, o tempo de prensagem, a quantidade de adesivo, o tipo de desmoldante e a temperatura deveriam ser diferentes para cada um dos tipos de resíduos. Por exemplo, para a fabricação de produtos com resíduo de MDF, os melhores resultados foram obtidos com o tempo de prensagem de 15 minutos, com 40\% de adesivo, em relação ao peso do resíduo de MDF, utilização de desmoldante à base de água, utilizado para prensagem de compostos e artigos de madeira que utilizam resinas de ureia formol e resina melamínica, e temperatura de $90^{\circ} \mathrm{C}$. Para a fabricação dos produtos com o resíduo de madeira maciça (peroba e jequitibá foram os resíduos testados), os melhores resultados foram obtidos com o tempo de prensagem de 10 minutos, com 30\% de adesivo, utilização de um antiaderente como desmoldante, e temperatura de $120^{\circ} \mathrm{C}$ (Tabela 2 ).

Tabela 2 - Variações na produção em relação ao tipo de resíduo utilizado

\begin{tabular}{lcccc}
\hline Resíduo & Tempo de prensagem & Quant. de adesivo & Desmoldante & Temperatura \\
\hline MDF & $15 \mathrm{~min}$ & $40 \%$ & à base de água & 90 o C \\
Madeira maciça & $10 \mathrm{~min}$ & $30 \%$ & antiaderente & 120 oC \\
\hline
\end{tabular}

Fonte: Elaborado pelos autores 
A figura 8 e a figura 9 retratam alguns produtos fabricados a partir dos moldes.

Figura 8: Porta-copo produzido a partir do molde.

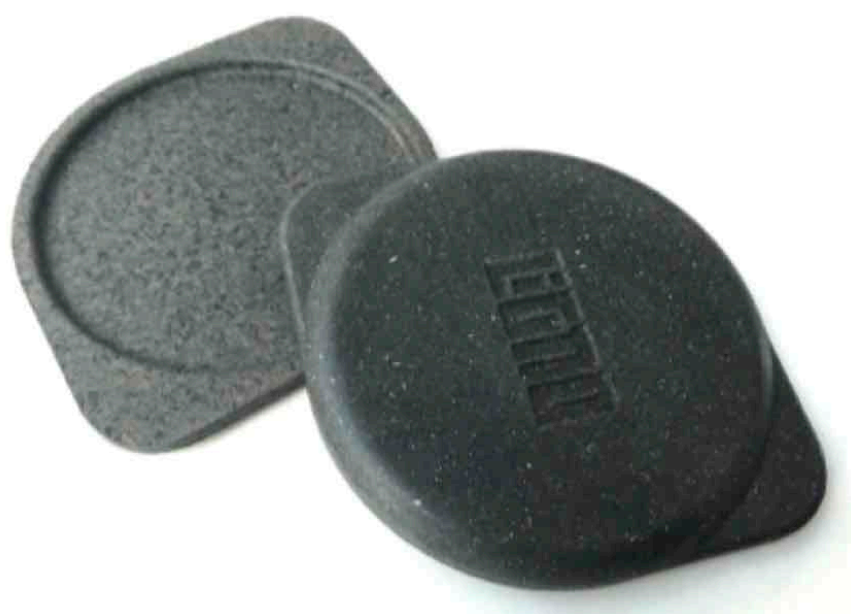

Fonte: Elaborada pelos autores.

Figura 9: Bowl produzido a partir do molde. Imagem (A) peça produzida com resíduo de MDF tingido de azul; imagem (B) com resíduo de madeira maciça de peroba; imagem (C) conjunto montado, demonstrando como se encaixam; e (D) peças com resíduo de MDF em diversas cores.
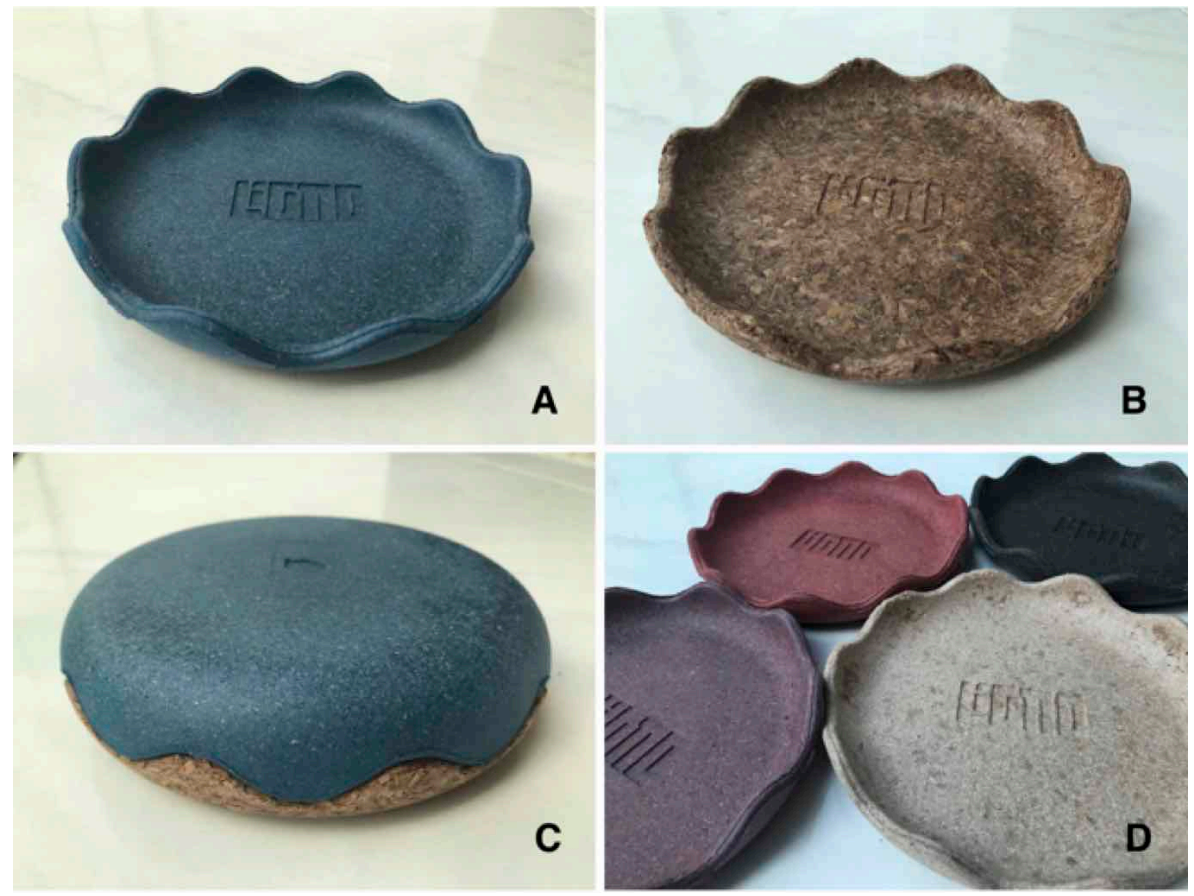

Fonte: Elaborada pelos autores 


\subsection{Solicitação de patente e registro}

Como resultado, solicitou-se patente para esse novo material / processo, denominado LIGNO. Além disso, solicitou-se pedido de proteção industrial para os produtos desenvolvidos: configuração aplicada em tigelas, para a linha de bowl, e configuração aplicada em luminária. Por fim, solicitou-se o registro da marca LIGNO.

\section{Considerações finais}

Foram muitas as descobertas e os aprendizados relacionados ao desenvolvimento deste novo material. Dentre elas, destaca-se o potencial inovador do compósito, tanto como solução sócio ambiental para a destinação sustentável destes resíduos, quanto como matéria prima com características distintas e desejáveis para diversas aplicações em design.

Com base nos resultados alcançados até aqui é possível afirmar que é possível aproveitar melhor os resíduos gerados pelas indústrias moveleiras a partir da fabricação de produtos com alto valor agregado, contribuindo para o meio ambiente e para a sociedade, gerando mais emprego e renda.

A tecnologia desenvolvida tem relativa facilidade para se adequar à realidade da indústria moveleira, podendo ser transferida e integrada nos arranjos produtivos do setor, exigindo, para tanto, investimento compatível com o porte das empresas estudadas. Este fato evidencia mais claramente seu potencial de implementação e pode ser considerado como contribuição mais significativa deste trabalho em relação aos demais esforços na direção de soluções análogas para o problema abordado.

Os resultados alcançados demonstram que há contribuição significativa desta pesquisa para a área do Design (pelas possibilidades de aplicação em produtos), para a área de Engenharia de Materiais (pela capacidade de desenvolver aplicações para essa nova tecnologia), e sobretudo, para o setor moveleiro, pela possibilidade do aproveitamento do resíduo de MDF e de madeira maciça na fabricação de produtos.

\section{Agradecimentos}

Agradecemos ao CNPq pelo apoio financeiro para a realização desta pesquisa; à PróReitoria de Pesquisa da Universidade Federal de Minas Gerais pelas bolsas de iniciação científica concedidas aos alunos; ao Sindimov-MG, pela parceria e apoio; e em especial aos alunos bolsistas e aos voluntários que tanto contribuíram para os resultados alcançados.

\section{Referências bibliográficas}

ABREU, Luciana Barbosa de; MENDES, Lourival Marin; SILVA, José Reinaldo Moreira da. Aproveitamento de resíduos de painéis de madeira gerados pela indústria moveleira na produção de pequenos objetos. Revista Árvore, Viçosa-MG, v.33, n.1, p.171-177, 2009.

Associação Brasileira de Normas Técnicas. ABNT NBR 14810-2:2013 - Painéis de partículas de média densidade - Parte 2: requisitos e métodos de ensaio. 
CIATEC A.C. Proceso y producto obtenido a partir de una mezcla aserrin y polimero reciclado utilizando desperdicio del procesado de madera. MX n. MX2011008552 (A), 12 ago. 2011, 20 fev. 2013.

CORRÊA, Glaucinei Rodrigues; DUARTE, Adriana Luisa; ABREU, Lucimar Guimarães de. Resíduos da Indústria Moveleira: Diagnóstico das Empresas Associadas ao SINDIMOV-MG, p. 4214-4225. In: Anais do 12 - Congresso Brasileiro de Pesquisa e Desenvolvimento em Design [= Blucher Design Proceedings, v. 9, n. 2]. São Paulo: Blucher, 2016. ISSN 2318-6968, DOI 10.5151/despro-ped20160362

FUNDAÇÃO DE AMPARO À PESQUISA DO ESTADO DE SÃO PAULO. Processo de obtenção de compósitos termoplásticos com resinas virgens ou recicladas reforçados com farinha de resíduo de madeira e/ou mdf e suas aplicações em produtos perfilados e componentes moldados por injeção para indústria moveleira, construção civil, decoração e paletes. BR n. PI 0802175-9 A2, 16 abr. 2008, 10 mar. 2009.

HEXION INC. Wood composites, methods of production, and methods of manufacture thereof. US n. US7803855B2, 25 jan. 2007, 28 set. 2010.

Lei 12.305 de 2 de agosto de 2010 - Política Nacional de Resíduos Sólidos.

Panorama do Setor Moveleiro no Brasil - ABIMÓVEL, 2006.

PEREIRA, Andréa Franco; CARVALHO, Laura de Souza Cota; PINTO, Ana Carolina de Oliveira. Resíduo de madeira: limites e possibilidades de seu uso como matéria-prima alternativa. In: Anais do $9^{\circ}$ Congresso Brasileiro de Pesquisa e Desenvolvimento em Design. Universidade Anhembi Morumbi, 2010. 